\title{
Legitimation Inferences: An Additional Component for the Toulmin Model
}

\section{G. THOMAS GOODNIGHT Northwestern University}

Key Words: Argument; argumentation; Toulmin model; controversy; legitimation; rhetoric; communication; public forum; informal logic; critical thinking.

Abstract: This paper argues that the choice of backing to certify the authority of a warrant requires a legitimation inference. When brought into question, such an inference becomes a claim defended by showing sound reasons for the selection of backing pertinent to a shared context. Legitimation controversies ensue when an attributed consensus meets objection. It is argued that attention to legitimation controversies renders the Toulmin model a more useful critical paradigm for investigating the development and risks of communicative reasoning in a public forum. The nomination of John Tower as Secretary of Defense is employed to illustrate how critical analysis of legitimation controversies reflexively expands the domain of inquiry for informal reasoning.

\section{I.}

Standing behind our warrants ... there will normally be other assurances, without which the warrants themselves would possess neither authority nor currency - these other things we may refer to as the backing (B) of the warrants. This "backing" of our warrants is something which we shall have to scrutinise very carefully: its precise relations to our data, claims, warrants and conditions of rebuttal deserve some clarification, for confusion at this point can lead to trouble later on. (Toulmin, The Uses of Argument, 1958, p. 103)

Why do interlocutors chose one form of backing over another? What happens when the relationship between backing and a warrant is challenged? How are questions of proper backing resolved? If the Toulmin model is to be deployed to analyze the arguments of public speakers, specialized fields, and everyday discourse, it is important to answer these questions. The choice among different kinds of backing is highly influential in determining the status of claims, the types of proof, and the range of warrants considered to be pertinent and sound. The authority, even the basic reasonableness, of an argument depends to a great extent on whether the proper choice of backing has been made and communicated. Yet, the nature and requirements of the inference that links warrant and backing has been little examined.

I contend that, in any given argument, the move from warrant to backing requires a distinct, communicative inference: namely, the provision of some good and sufficient reason that draws a connection between backing and warrant. This move I call a legitimation inference, constituted by the production of a convincing reason (for a real or hypothetical interlocutor) that shows an argument in whole, or in any of its component parts, to be certified by an appropriate, proper, or correct choice of backing.

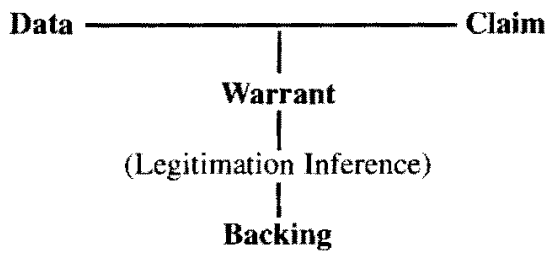

Figure I

In a warrant-using argument, legitimation inferences answer the question: why this field and not others? In a warrant-establishing argument, legitimation inferences become 
a special, complicated claim: The warrant is established by adducing valid reasons for a choice of backing, which itself offers legitimate grounds for reasoning in a commonly shared context. Valid reasons for a choice of backing pertinent to a context include proper inclusion of the audience, fair procedures for the evaluation of evidence, and appropriate norms of judgment.'

This essay will proceed to first show that the Toulmin model does not account adequately for the choice among possible backings for an argument; second, illustrate how dispute over the validity of legitimation claims plays a key role in public debate; and third, examine some of the consequences of legitimation controversies for the study of argumentation and communication. Thus, the essay works to recuperate the Toulmin model as an important critical tool by extending the study of practical argumentation into the complexities of communicative reasoning. ${ }^{2}$

\section{The Missing Link}

Toulmin's The Uses of Argument (1958) is a landmark study that reopened inquiry into the "practical business of argu mentation." For most of the 20th century, argumentation had been understood in terms of formal logic, and its concerns were Jargely restricted to formal validity. Toulmin sought to construct a model that would address arguments in use, thus encouraging the formal-pragmatic study of argumentation in everyday reasoning, the discourse of specialized fields, and public debate.

Toulmin's basic model is a molecular unit of argument that moves from data ("facts we appeal to as a foundation for the claim") to claim ("conclusion whose merits we are seeking to establish") by virtue of a warrant (a reason that authorizes the movement from data to claim). The qualifier (modal term) specifies the strength of relationship between data and claim, and the rebuttal (an announced reservation) specifies conditions of exception. The model is developed in relation to jurisprudential reasoning where evidence is used to establish the probability of claims.

Attached to any molecular unit of argument is backing. Backing provides "the grounds for regarding a warrant as generally acceptable" (p. 106). Whereas data are usually rendered explicit in practical argument, the backing is generally left "understood" as a kind of resource to draw upon should one be asked why the warrant is reliable. As Toulmin says, "Statements of warrants ... are hypothetical bridge-like statements, but the backing for warrants can be expressed in the form of categorical statements of fact quite as well as can the data appealed to in direct support of our conclusions" (1958, p. 105).

The following example in The Uses of Argument is well-known. (D) Harty was born in Bermuda. It can be inferred that (C) he is a British subject, because (W) a person born in Bermuda generally will be a British subject. The backing (B) consists of "The following statues and other legal provisions." Thus, backing stands to the warrant as a secured, general rule buttressing an unsecured-but-reasonable inference, invoked to draw a conclusion from what are held as relevant facts. Although all backing presumably serves the same function of authoritatively securing the warrant, Toulmin notes that the kinds of backing available are subject to "variability or field-dependence" (p. 104). Thus, for our old friend Harry, we may back our warrant by referring to legal statutes, or statistical probability, or general views on birth place and national identity. Toulmin reminds us that the choice of backing is important, and choices among backing do not lead to co-equivalent reasons for supporting a warrant. "The kind of backing we must point to if we are to establish its [a warrant's] authority will change greatly as we move from one field of argument to another" (p. 104). How are such choices made and secured? 
The Uses of Argument does not provide an answer to this question, but Toulmin, Rieke and Janik (1979) take it up:

Certain types of warrants rely for their soundness and relevance (as in statute law) on deliberative collective human decisions. Others (as in natural science) rely on our recognition of general patterns in the world of nature. Others (as in much of our everyday understanding of human actions and motives) rely on familiar, unrecognized regularities in human affairs. In the last resort, how far arguments of any particular type depend on backing of one kind or another-how far on collective decisions, how far on discoveries about nature, how far on familiarity with human affairs--is something that varies greatly from one context [my emphasis] of argumentation to another. (pp. 62-63)

In short, the choice of backing depends upon the fit between the warrant in question and a controlling context. Warrants about relationships in the natural world are backed by a knowledge base certified by the fields of natural science. Warrants about prudent conduct in everyday human actions are drawn from a shared base of common or social knowledge. Warrants about institutional judgments and regulations are backed by the codes and procedures of specialized enterprises like the law. So long as there is a congruence between the claim in question and the expectations of interlocutors that reason is funded by relevant backing, arguments appear to be governed by a relatively unambiguous context. Note, though, that the "context" depends upon an attribution of consensus between the interlocutors on what backing is most pertinent for the argument at hand. ${ }^{3}$

From the perspective of argumentation as a process of making reasonable conclusions, the contextual relationship between warrant and backing appears seamless. If we are trying to establish a conclusion, we draw warrants from relevant regions of knowledge or experience to secure the relation of data to claim. Such warrant- using arguments foreground the linking of datawarrant-claim. The backing functions as a source of authority or certification when building arguments of a certain kind or type. Thus, Toulmin, Rieke and Janik write of the "context" as a clear-cut relationship between a data-warrant-claim and a field, or knowledge domain. The attributed consensus of a common context renders the choice of backing unproblematic.

It can be conceded that in many practical arguments, context appears to be singular, relatively clear, and uncontested. In a court of law, one expects legal backing to support a warrant. In a conversation, one expects general knowledge. In scientific argument, arguments are backed by procedures and codes vested in a field. Yet, because argumentation involves interested others, who are addressed, implicitly or explicitly, such a choice may or may not be found acceptable (Johnstone, 1973; Farrell, 1977). Thus, an interlocutor must be prepared to defend the choice of backing by showing the validity of the inference that there are shared, sound reasons for chosing to develop an argument grounded upon a certain kind of backing. Just as the other components of the Toulmin model provide places to join disagreement, in principle this communicative inference, too, is always available for inspection and argumentative development.

When we shift perspectives, from drawing a reasonable conclusion to making a convincing argument, the importance of choosing contexts becomes apparent. Suppose that there are multiple fields which are relevant to the settlement of a claim, and each possible choice of backing offers some support, but none is determinative. To the extent that a warrant (or a group of supporting warrants) can be shown to be probably true in multiple contexts, an argument gains the strength of a consensus. If Harry is legally, statistically, and politically likely to be a British subject because of his Bermudian birth, then a very convincing argument can be made. 
The claim gathers strength in a persuasive sense, not because of trickery or strategic guile, but because the convergence of support increases the probability of encountering an interlocutor or audience who is likely to agree that our selection of backing is authoritative. The argument also gathers strength because it is supported from several different standpoints, together rounding out the substantive identity of the claim by demonstrating that Harry is "a British subject" in the fullest sense. This rounding out strengthens the argument by shrinking the grounds of possible rebuttal. Finally, the argument becomes convincing because the interlocutor has demonstrated willingness to examine all relevant fields in deriving a judgment; in other words, the claim is regarded as trustworthy because it has been fairly considered. In these instances, the legitimacy of our choice of backing is validated by the demonstrated convergence of backings; hence, an argument becomes more convincing by virtue of its consensual development.

So long as all relevant evidence and warrants support a claim, the choice among alternative backings to contextualize an argument remains uncontroversial. Claims can be supported by warrants grounded in knowledge domains that have little or nothing to do with one another, and the choice of backing makes little difference to the acceptability or strength of an argument because support all points unequivocally in the same direction. The legitimacy of the choice of backing would not be at issue; therefore, the reasons for such a choice may remain an implicit inference of the argument; the unquestioned inference being that all or the most relevant fields have been consulted and support our conclusion.

Arguments become interesting when the choices among available backings either do not all point in the same direction, or point in the same direction but with varying degrees of certainty. Then the selection of a single ground, or the arrangement of grounds in a hierarchy of importance, becomes a noticeably accountable inference, and as such, a legitimation claim. Legitimation inferences are reasons that account for the choice of backing as relevant, authoritative, and proper. Legitimation claims may be denied by raising objections to the choice of backing which constrains and authorizes particular kinds of data and warrants while excluding or restricting others. When the choice of grounds upon which an argument is developed is questioned, a legitimation controversy ensues. A legitimation controversy brings the ordinary conventions of reasoning that ground warrants to notice, gives rise to debate over the validity of criteria for selecting such grounds, and tests the viability of a shared context of reasoning and communication (Goodnight, 1991, 1992).

\section{Legitimation Controversy}

In this section, I will illustrate how the choice of backing itself functions as an important part of an argument. The example is drawn from a United States Senate confirmation debate in 1988. Newly elected President George Bush chose the former Senator from Texas, arms negotiator, and lobbyist, John Tower, to be his nominee for Secretary of Defense. Having served a long term in the Senate, Mr. Tower's public record and private life were well known by many of his colleagues. Additionally, the Federal Bureau of Investigation conducted a background check for the confir-mation proceedings, gathering additional opinions on his character and qualifications. The Senate agreed that the materials from the confidential FBI interviews would not be discussed publicly, although each Senator was given private access to the sequestered report. Absent a public discussion on the full "evidence," the argumentation turned upon the questions of whether and how the proof warranted the conclusion that Tower should be confirmed as Secretary of Defense. 
At this point, let us critically reconstruct the central argument of the debate along the lines of the Toulmin model. Data: The actions of John Tower as Senator, arms negotiator, and lobbyist. Warrant: The actions of John Tower show that he is a person of competence, trustworthiness, and good will. Claim: John Tower should be confirmed as Secretary of Defense. Rebutfal: Unless there are telling instances sufficient to warrant a contrary assessment. Qualifier: Probably. ${ }^{4}$

This structure resembles closely a practical syllogism where argumentation takes on the burden of deliberation over an action contemplated by a community. Note, though, that this argument is constrained by a special context. Since much of the "data" is unavailable for common assessment, and since the claim forces an up or down choice, a great deal of importance is put on argumentation concerning the acceptability of the warrant, which in this case constitutes a general determination of judgment. Thus, there is great stress to render valid the choice of backing, and thereby legitimate the warrant. The context requires that each advocate show that his or her own support for the warrant is validly grounded, and attack the legitimacy of alternative backing that would lead to a different conclusion. Consider the three main legitimation arguments.

(1) The Question of Consensus. At the core of the legitimation controversy was a dispute over the proper means of consensus formation for the Senate as a deliberating body. What mode of participation would honor the collective obligation of the Senate to affirm the "separation of powers", thereby granting the Executive its own working Cabinet and, equally important, satisfying the Constitutional obligation for each individual Senator to appropriately "advise and consent"?

Tower proponents argued that the duty of the Senate resided, not in individual determinations of preference, but in honoring a bi-partisan tradition that grants presump- tion to Presidential nominees. Senator Jeffords said:

\begin{abstract}
Historically, only on rare occasions has the Senate refused to confirm a nominee, even though the Senate has frequently disagreed with the nominee or the President on certain aspects of policy or personality. Custom indicates a general feeling that the President has the right to name his own staff. (S 2430) $)^{5}$
\end{abstract}

Since only eight Presidential nominations had been turned down in the history of the United States, and none in the first term of a newly elected President, tradition creates a strong presumption that objections to a candidate must be grave and well supported to be legitimate concerns. Thus the "advise and consent" clause of the Constitution was read as a mandate to set aside policy differences and support the President.

There are valid reasons supporting the presumption of favor for the President's candidate, supporters argued, because such bi-partisanship sends a signal to foreign governments of the peaceful transition of power, and it allows the Chief Executive to develop a working Cabinet. As Senator Danforth put it, "The question is not whether we should substitute our judgment for the judgment of the President of the United States but whether we should give great deference to the President in selection of his own management team for his own administration" (\$ 2167). Should tradition be ignored, then the capacity of the Senate to achieve consensus would be seriously undermined. If the criteria were personal preference for an administrative appointment, Domenici of New Mexico argued, the Senate, "could not get enough votes for anyone's nominee, because we all think we know how to do it better or we think somebody is better" (S 2319).

Those opposing Tower worked to undermine the general presumption of Presidential choice. Senator Gore reminded the Republicans that the Senate had already confirmed twenty appointments on votes 
of 100 or 99 to zero. "For anyone to suggest that we have dealt with the nominations of this President in a partisan fashion," he said, "is for that person to simply ignore the record, which is overpowering on that point" (S 2309). And on the specific issue of the legitimacy of challenging a single candidate, Democratic Senators told the opposition that the Constitution did not intend for Congress to be a "rubber stamp." Senator Pryor reached back into history to show a consensus on this point, and said that the founding fathers "saw that ultimately our conclusions would belong to us and to us alone" ( $S$ 2182). Others drew on more recent history and observed that the same Senators, who were arguing that the tradition of deference should be decisive grounds for participation in the obligation to "advise and consent" now, had argued for the duty of personal judgment when the Democratic nominee, Paul Warnke, had been up for confirmation during the Carter Presidency (Mitchell, S 2297). Yet, as Arlen Specter argued, it is not the "views" of Senators which are important but the "judgment of the Senate" embodied in the history of only eight rejections that constitutes the presumptive grounds of deference (S 2298).

Once the Constitution was interpreted so as to stress the obligation of individual judgment on the part of each Senator, those opposing Tower could shift backing from adherence to tradition to, as Senator Cranston claimed, a choice governed by his own "good conscience" (S 2184). Similarly, Kerry explained the decision of the House Armed Services Committee, which split nine Republicans for the nomination and eleven Democrats against, as "a vote not of partisanship, but a vote of conscience" (S 2452). This change of grounds for participation decidedly undermined the strength of presumption in favor of the President's wishes. For example, Senator Breaux found that the satisfaction for his own decision required that one look "for the very best that we can find in the nation"
(S 2166). Pryor's test was even simpler: "Is this man going to be someone in the Department of Defense who is going to create problems or solve problems" (S 2182)? Shunting aside tradition entirely, Tower's chief antagonist Senator Exon said: "I defer to the President, except when I think he is critically wrong" (S 2168).

Those on the Republican side of the aisle found the appeal to "conscience" unpersuasive, even hypocritical. "Does anyone here really doubt that if a Democratic President had sent up John Tower as a nominee, he would have been confirmed weeks ago?" (S 2427), asked McClure, with more than a little bit of derision. Yet, Pryor responded that the duty of representing constituents might have been better served if less deference and greater investigation had been accorded to the likes of James Watt and Ed Meese, Cabinet members thought generally to be highly partisan themselves (S 2182).

(2) The Question of Evidence. The majority of United States Senators are attorneys, and so when it comes to questions of evidence and procedural fairness in determining fitness for high office legal standards seem a natural context for determining the validity of proof and the legitimacy of procedural guidelines. But, Senators are politicians, too, and the public sphere has different standards for fairness and determination of proof. In this legitimation controversy the identities of Senators as attorneys and as politicians were drawn into opposition.

Advocates of the nominee made a case for the candidate based on legal standards. Many Senators commented on the accomplishments of Tower's career, offering personal testimonial and public appraisal. They pointed out that, in fact, there was no sworn public testimony to the contrary, and so no valid proof existed that would be sufficient to indict Tower of wrong doing. True, Tower did admit that he had a drinking problem in the 1970 s and he did go through a divorce, but whatever "personal" 
problems he might have had-and everyone has some personal problems-these did not incapacitate his judgment and role as a "public" official. Senator Boschwitz summarized:

This nominee is a former member of the Senate, for 24 years no less. Seventy Members of the U.S. Senate, as many of my colleagues have said, have served with him and none, not a single one, has seen him inebriated or in conduct unbecoming the office. In addition, one and all agree, everybody agrees that Senator Tower is enormously well qualified. In fact, we confirmed him for another post by voice vote in recent years, and presumably there was an FBI report and some of these things came out, but yet we confirmed him without opposition, (\$ 2413)

The "some of these things" were allegations of "womanizing" and "alcoholism" that were made by unnamed sources in the secret FBI report, partially leaked to the press during the preliminary hearings on the nomination.

Proponents were quick to brand such "rumors" as illegitimate sources of proof. "I practiced law for eighteen years in the town of Cody, WY, and I never saw evidence like this that could send a guy to the clink or dispose of him," opined Allan Simpson (S 2163). Should such evidence be treated seriously, then a precedent would be set where secret, unchallenged testimony could ruin public lives. "Whatever happened to due process?" Rudman asked, noting that Tower was not given the opportunity to confront his accusers (S 2225). "The confirmation process has become a trial," said Symms (S 2419), and Dole warned that the judgment of the Senate was at risk, for this case would determine whether Senators would adhere to valid testimony or be swayed by rumor from unknown sources spread by the press. "Let us treat Tower fairly," Dole admonished (S 2295).

Opponents of Tower were quick to shift the grounds of argument by denying the "trial" as a governing context for determination of evidence, and legal "due process" as the only valid rule for fair discussion. Senator Kohl shifted the contextual definition of the situation: "We are not deciding if John Tower is guilty or innocent of substance abuse or conflict of interest charges; we are deciding if he is the person who ought to be Secretary of Defense. And that is not a legal decision. It is a policy decision" (S 2463). Senator Gore agreed, and specified the realm relevant to policy discussion: "A confirmation hearing is not a court of law. Members of the Senate do not function as a judge and jury when they give advice and consent to important nominations. They are exercising political judgment, often under very uncertain conditions" (S 2310). If the proper backing for evidentiary debate is politics, then Tower had not been subjected to an unfair process. The Senator from Virginia reasoned: "Mr. Tower has had ample opportunities to make his case and we listened. He made his case before the committee in public and in executive session. He has been on the airwaves. He has been on television and he has commanded the center of attention in the print media" (S 2341). Thus, the criteria for "fairness" was asserted to be public access, not legal process. Tower was not "tried" by an unfair presentation of "evidence", since all political office seekers must submit themselves to the risks of public debate. And the Democrats pointed out that the Republicans, themselves, had helped to craft the rules which sequestered the FBI reports.

(3) The Question of Competence. Whereas the Constitutional argument worked to set a presumption for the Senate as an audience, and the controversy over the fairness of procedure strove to establish proof standards, the discussion of competence brought into question the norms of proper judgment. The issue of competence thus turned upon how and whether the private life of a candidate should raise concerns that outweigh the public record. 
Tower's friends, again and again, reminded the Senate that the former Chair of the Armed Services Committee and Geneva negotiator had an "unblemished" public career, and, indeed, no where during the debate did any Senator question Tower's accomplishments and expertise in Defense matters. Great frustration was expressed by Bob Dole, the Republican whip, that the public record seemed to be irrelevant to the opposition:

Has anybody risen to this floor and said Senator Tower is incompetent, John Tower does not understand defense, John Tower does not understand the Senate or the Congress or the budget? No not one. It has all been these tangential issues that somebody read a report somewhere and it said he was drinking excessively. (S 2296)

These "tangential" issues of behavior in private life-Tower's relationship with women, his use of alcohol, and his work as a defense industry consultant after serving as U.S. arms negotiator-were held to be unfair grounds for determination of competence. As long as he had done nothing illegal, and had not been impaired in the performance of his duties, or had not publicly embarrassed his office, his friends argued, then matters of private conduct are improper grounds for public evaluation. Senator Jeffords found dark questions raised by what he believed to be a new standard of judgment raised in the debate:

\footnotetext{
If we sanction rumors of private conduct as appropriate grounds for rejection of a nominee, does it not then become appropriate, if not the duty of the press, to report all allegations about a nominee's private conduct. Are we not then giving it license, even the obligation, to probe into the private lives of all other public officials? Could not this be construed as sanctioning scandal sheet methodology? (S 2431-2432)
}

If, in this case, private behavior alone were established as adequate grounds for judgment of public competence, then a new standard would be legitimated, a test of competence that few Senators themselves could pass. Further, otherwise competent candidates would be discouraged from seeking public office.

Those opposing Tower were careful to narrow their arguments by asserting that it is the special nature of defense as a field which makes private conduct publicly relevant. Sam Nunn said that the Senate was not discussing a "normal Cabinet position," but choosing a person who was "second" in the Chain of Command for all our nuclear and conventional military forces (S 2416), thereby implying that even if a person given to alcohol can perform well in public settings, the twenty-four hour a day requirements of nuclear deterrence demand total sobriety. Other Senators pointed out that the Military Code required the highest standards of moral conduct, and Tower's private behavior would not set an example requisite to maintaining morale. Still other Senators chose to distance themselves from these "moral" issues and emphasized the "apparent" conflict of interest in the former arms negotiator's "rap id" move to industry. "The appearance of conflict of interest and the real conflict are simply too strong," concluded Kerry, and such a problem is especially salient "at a time when the Pentagon is screaming for the toughest kind of judgments and leadership with respect to the procurement process" (S 2452).

Many Senators found these new standards of judgment, that would weakenperhaps even erase - the line between pub lic and private life, deeply troubling. McConnell reminded the Senators, "As we all know, most of us could not meet the standard that has been made up for John Tower. Many members on the Armed Service Committee and off accept honoraria from defense contractors, accept PAC contributions from defense contractors" (S 2313). To move the fulcrum of judgment from the question of "Did he do anything wrong?" to whether he gave the "appearance" of wrong doing, according to Arlen Specter was to embrace an unfair and 
"shifting standard for confirmation which is tailored especially to John Tower" (S 2299).

On March 9, the Senate voted 53-47 to reject the candidate. Forty-four Republicans and three Democrats voted for the nomination. Fifty-two Democrats and one Republican, Sen. Nancy L Kassebaum of Kansas, voted against. For Kassebaum, the evidence of improper conduct was determinative (S 2461). ${ }^{6}$

\section{Legitimation and Practical Reason}

Any reconstruction of arguments offered in public debate is constrained by the fact that the "real reasons" for supporting or opposing a candidate, a policy, or a law may be hidden from view. In the Tower controversy, for example, some critics of the debate concluded that opposition was fierce simply because in his tenure as Chair of the Armed Services Committee, John Tower had "rubbed a lot of people the wrong way." The legitimation claims, then, could be construed as strategically crafted appearances or pretexts to provide publicly acceptable reasons for settling private scores. But as the Senate engaged in common deliberation, the resulting legitimation controversy put much more than the nomination itself in jeopardy. The conventions governing common communicative reasoning were submitted to vigorous debate, narrowing the realm of legitimate differences and commonly accepted grounds for decisions.

Legitimation claims can create room for respecting differences of opinion by offering good and sufficient reason why a certain choice of backing is proper. In most cases of practical argument, legitimation inferences are not at issue because an interlocutor correctly attributes a common context or chooses from a generally acceptable range of backing. Even where there is disagreement on what backing is best, differences can be reasonably discussed-so long as opponents respect the choice of backing advanced by another. Legitimation inferences become contested when the stakes of the argument are important, and the choice of backing leads to different conclusions about the nature and strength of the warrant linking relevant data to claim. In such instances, legitimation claims are challenged, and debate ensues over how an audience should properly participate, evaluate evidence, and render judgment.

A legitimation controversy proceeds by raising questions and adducing support for backing. Interlocutors may draw upon contextual definitions to support the wisdom of interpreting an argument as most relevant or pertinent to social knowledge, institutional rules, public consensus, or the constraints of the natural world. The question becomes what backing should be regarded as determinative, and whether the reasons for such a determination are valid.

In legitimation controversies, one often finds warrant-establishing arguments. A warrant establishing argument is one where a new connection between data and claim becomes authorized. ${ }^{7}$ Because a legitimation controversy focuses upon the proper reasons for decision, the outcome of such a debate consensually strengthens certain warrants while depreciating others. Whatever "private" motives an interlocutor might possess, public debate requires that backing for key warrants be thoughtfully chosen, since the validity of such choices are themselves submitted to debate. Legitimation claims may confirm or overturn previous conventional authorization of warrants, and so establish precedents with presumptive validity. If a warrant is sufficient in one case, then its advocate can be held accountable to rules of consistency in another. Thus, a legitimation claim establishes a warrant in a double sense. A newly posited relation between a given data and claim is held to be backed well enough to be warranted, and the reasons validating a choice of backing for claims of this kind are confirmed as within the domain of responsible advocacy. 
The consequences of legitimation controversy may be positive or negative. On the positive side, a community of advocates are forced to display criteria for judgment in an open, public forum. Thus, the conventional contexts authorizing the links between claims and evidence are submitted to examination and considered discussion. Private motives are constrained by the necessity of demonstrating valid public judgment, a judgment offering reasons to secure the common good. Such discussion may have dire consequences, however. Questioning how well an interlocutor fulfills appropriate duties, adheres to a fair process of argument, and exercises sound judgment, may depreciate the commonly attributed good will, trustworthiness, and competence requisite for open discussion. The Tower debate became "a ruckus" not only because of the divisiveness of the issue, but also because the legitimation controversy called into question the validity conditions for legitimate reasoning among the Senators as a deliberating body.

When the respect for legitimate grounds for differences is reduced, the communicative argument of a forum may become systematically distorted or privatized. ${ }^{8}$ Once common grounds are shredded, the tattered rules of decorum that remain offer weak ties for common deliberation. "It is not a good day for the U.S. Senate," concluded Senator Symms (S 2419), and the highly partisan confirmation and "ethics" hearings in the years following the Tower debate have brought the United States Senate into disrepute.

While critical inquiry into a legitimation controversy allows us to come to terms with the fate of a deliberating body, it can also teach us more. In speaking to the question of the nomination, interlocutors brought into focus the uncertain requirements of legitimate deliberation. So our inquiry was able to uncover some important, open-ended questions concerning the normative development of argumentation. To what extent and when should the requirements of consensus-making grounded in tradition govern choice, or should a common choice always be featured as a duty to conscience? Should standards for evidence in public speech meet the norms of legal process, or should the process of public debate be entirely open-ended? Should the public record of a nominee determine fitness for office, or should norms of private conduct serve as relevant grounds for determining public competence? While speculation on the answers to these questions is beyond the scope of this essay, suffice it to say that the illustration shows that a legitimation controversy directs attention to important questions about argumentation as a communicative practice, and so reflexively expands our field of inquiry.

\section{Conclusion}

Jürgen Habermas has drawn a distinction between "validity" conditions of discourse and legitimation "displays" (1975, $1984,1987,1990$ ). While the former demonstrate a willingness to support argument in an open way aimed at understanding, the latter are consigned to the strategic realm and are aimed to stir up support through appeals to "mass loyalty." In this essay, I have tried to point out that legitimation questions fuse the strategic and the communicative, and so must be examined as a special kind of inference. When advocates engage in debate where the proof and claim are not submitted to further development, the choice of backing for a warrant becomes quite important. Under this condition, advocates adduce reasons to show that their decision is supported by acceptable criteria of good judgment and a reasonable interpretation of appropriate argumentative procedures and obligations. While such contextual elements are normally implicit, a legitimation controversy opens unspoken conventions to inspection, by inviting reason giving that makes a case 
for a choice of backing. The critical reconstruction of such argumentative engagements permits inspection of the norms of advocacy. By focusing upon what is often left implicit-the valid concerns that certify a legitimate selection of backing-this study opens up a place where we can learn from the exigencies of practical reasoning.

\section{Notes}

1 Farrell considers conditions for the validity of a rhetorical argument. These include an assessment of "soundness" based on considerations of "i. The complicity of audience in argumentative development; ii. The probable relationship between rhetorical argument and judgment; iii. The normative force of knowledge presumed and created by rhetorical argument (1977, p 142)." A legitimation controversy arises out of validity objections to whether and how audiences have been invited to participate, the accessibility and propriety of reasons for judgment, and the norms which are adduced as presumptions for (a) grounding the development of communicative reasoning and (b) linking knowledge to conduct.

2 In spite of some critique, the Toulmin model has generally been accepted as a useful way to explain basic components of practical argumentation. The model has proven less adaptable to critical analysis of arguments in use, and this problem has opened Toulmin's perspective on argumentation to attack. One the one hand, Willard $(1976,1978 \mathrm{a}, 1978 \mathrm{~b}, 1981)$ attacks the "diagrammatic" quality of the Toulmin model because it requires analysis by abstraction from a "text" based on discursive argument, which is itself an abstraction from argumentation that is always accompanied by discursive and nondiscursive elements. On the other hand, Burleson and Kneupper find the model useful for diagramming "meta-messages" in social cognition and construction of reality (Burleson, 1979, 1980; Kneupper 1978, 1979, 1980, 1981). Despite their differences, Willard, Burleson, and Kneupper wish to ground argumentation in the theoretical discourse of social psychology, a move which is unwarrantedly exempted from basic reflexivity conditions of communication. This essay argues that the usefulness of the model as a critical paradigm can be greatly expanded by the addition of a component which isolates the communicative requirements in practice of rendering a valid contextual judgment. Thus, the field of argumentation is opened up to critical inquiry that reflexively engages controversies, thereby learning how the communicative processes of argumentation are developed and revised over time. The aim of the essay seems consistent with Toulmin's observation: "These practical debates [about environmental policy, medical ethics, judicial practice, or nuclear politics] are no longer "applied philosophy' they are philosophy itself" (1988, p. 345). The task of critical inquiry is to find emergent standards for practical reasoning resulting from legitimation controversy.

3 Presumably, the selection of backing extends to questions about the authorization of grounds with which we can assert "facts" as facts.

4 The enthymematic premise that completes the formal argument is: A person of competence, trustworthiness, and good will is fit to be Secretary of Defense. The formal completion of the argument makes no "substantive" difference to the claim, but this completion of the premise by the audience provides the implicit criteria for thinking and arguing about the nomination. The debate turned on whether and how the "ethos" conditions were related among themselves and should be evaluated in the specific case. In this manner, public argument invites rhetorical cognition.

5 All references to the Tower debate are from the Conqressional Record, March 6-9, 1988.

6 Those who read the Congressional debate will be struck by the repetitive quality of the argumentation. The initial report of the Armed Services Committee creates a framework for argumentation which is contested, elaborated, and extended during the debate. It seems that legitimation controversy draws in the members of a deliberating body to use argument as a way of testifying to the strength of presumptions and the validity of argument conditions.

7 Toulmin says: "Warrant-establishing arguments will be, by contrast, such arguments as one might find in a scientific paper, in which 
the acceptability of a novel warrant is made clear by applying it successively in a number of cases in which both 'data' and 'conclusion' have been independently verified (1958, 120)." How a warrant is legitimately established presumably will differ across fields and different sorts of backing. The ability to establish a warrant turns upon a grant of legitimacy to the appropriateness of a reason which is unexpectedly relevant or determinative.

8 The communication of a deliberating body can become distorted in the opposite way as well. If too much deference is given to the reasons for deriving a valid judgment, then the claims to legitimacy become honorific coverings for private interests.

\section{References}

Burleson, Brant R. (1979). "On the Analysis and Criticism of Arguments: Some Theoretical and Methodological Considerations," Journal of the American Forensic Association, 15, 137-147.

Burleson, Brant R. (1980). "The Place of NonDiscursive Symbolism. Formal Characterizations, and Hermeneutics in Argument Analysis and Criticism," Journal of the American Forensic Association, 16, 222-231.

Farrell, Thomas B. (1977). "Validity and Rationality: The Rhetorical Constituents of Argumentative Form," Joumal of the American Forensic Association, 13, 142-149.

Goodnight, G. Thomas (1991). "Controversy." In Donn W. Parson (Ed.), Argument in Controversy: Proceedings of the Seventh SCA/AFA Conference on Argumentation (pp. 1-13). Annandale, VA: Speech Communication Association.

Goodnight, G. Thomas (1992). "Rhetoric, Legitimation, and the End of the Cold War; Ronald Reagan at the Moscow Summit, 1988." In Michael Weiler \& W. Barnett Pearce (Eds.), Reagan and Public Discourse in America (pp. 43-71). Tuscaloosa: University of Alabama Press.

Habermas, Jürgen (1990). "Discourse Ethics: Notes on a Program of Philosophical Justification." In S. Benhabib \& F. Dallmayr (Eds.), The Communicative Ethics Controversy (pp. 60-110). Cambridge: MIT Press.

Habermas, Jürgen (1975). Legitimation Crisis (Thomas McCarthy, Trans.). Boston: Beacon Press.

Habermas, Jürgen (1984). The Theory of Communicative Action, Vol. l: Reason and the Rationalization of Society (Thomas McCarthy, Trans.). Boston: Beacon Press.
Habermas, Jürgen (1987). The Theory of Contmunicative Action, Yol 2: Lifeworld and System: A Critique of Functionalist Reason (Thomas McCarthy, Trans.). Boston: Beacon Press.

Johnstone, Henry (1973). "Rationality and Rhetoric in Philosophy," Quarterly Journal of Speech, 59, 381-389.

Kneupper, Charles W. (1978). "On Argument and Diagrams," Journal of the Anterican Forensic Association, 14, 181-186.

Kneupper, Charles W. (1981). "Argument: A Social Constructivist Perspective," Journal of the American Forensic Association, 17, 183-189.

Toulmin, Stephen (1958). The Uses of Argument. Cambridge: Cambridge University Press.

Toulmin, Stephen, Richard Rieke \& Allan Janik (1979). An Introduction to Reasoning. New York: MacMillan

Toulmin, Stephen (1988). "The Recovery of Practical Philosophy," The American Scholar, $57,337-352$.

Willard, Charles A. (1976). "On the Utility of Descriptive Diagrams for the Analysis and Criticism of Arguments," Communication Monographs, 43, 308-319.

Willard, Charles A. (1978). "Argument as NonDiscursive Symbolism," Journal of the American Forensic Association, 14, 187-193.

Willard, Charles A. (1981). "The Status of the Non-Discursiveness Thesis," Journal of the American Forensic Association, 17, 190-214.

\section{G. THOMAS GOODNIGHT \\ DEPARTMENT OF COMMUNICATION STUDIES NORTHWESTERN UNIVERSITY \\ 1815 CHICAGO AVENUE \\ EVANSTON, IL 60201}

